\title{
SIMULAÇÃO DE DESFOLHAS EM DIFERENTES ESTÁDIOS VEGETATIVO NA CULTURA DA SOJA
}

Murilo Alberto Santos ${ }^{1}$, Emerson Trogello ${ }^{1}$, Dheynne Alves Vieira ${ }^{2}$, Rhayf Eduardo Rodrigues ${ }^{1}$, Ana Carolina Lima Ribeiro ${ }^{1}$, Alcir José Modolo ${ }^{3}$, Murilo Mesquita Baesso ${ }^{4}$

${ }^{1}$ Instituto Federal Goiano - IFGOIANO, Programa de Pós-Graduação em Olericultura, Morrinhos, GO. Instituto Federal Goiano - IFGOIANO, Programa de Pós-graduação em Zootecnia, Rio Verde, GO. ${ }^{3}$ Universidade Tecnológica Federal do Paraná - UTFPR, Programa de Pós-Graduação em Agronomia. ${ }^{4}$ Universidade de São Paulo - USP, Pirassununga, SP. Email: muriloengenheiroagronomo@gmail.com

\section{RESUMO}

A cultura da soja, durante todo seu ciclo, está susceptível ao ataque de insetos-praga que podem reduzir sua produtividade final. Objetivou-se com este trabalho avaliar o efeito de desfolhas artificiais em diferentes estádios vegetativos na cultura da soja. $O$ experimento foi implantado na área experimental do Instituto Federal Goiano - Campus Morrinhos e conduzido em delineamento com blocos ao acaso, com oito tratamentos e quatro repetições. A cultivar BRS Valiosa RR foi submetida aos seguintes tratamentos: T0: sem desfolha; T1: remoção de um folíolo por trifólio em V2 até V8; T2 remoção de um folíolo por trifólio em V3 até V8; e assim sucessivamente até chegar ao último tratamento T7: remoção de um folíolo por trifólio em V8. As variáveis analisadas foram: altura de plantas, altura de inserção da 1o vagem, índice de clorofila, número de ramos por planta, número de vagens por planta, número de grãos por vagem, peso de mil grãos e produtividade final da cultura. Os dados foram submetidos à análise de variância pelo teste de Scott-Knott a $5 \%$ de probabilidade, por meio do software ASSISTAT. Conclui-se que desfolhas contínuas em nível de $33 \%$ nos estádios iniciais da cultura reduz o porte da planta, o número de vagens por planta e a produtividade final na cultura da soja.

Palavras-chave: Glycine max; manejo integrado de pragas; produtividade; redução; trifólio.

\section{SIMULATION DEFOLIATION IN DIFFERENT STAGES VEGETATIVE IN SOYBEAN CROP}

\section{ABSTRACT}

Soybean crop, throughout its cycle, is susceptible to insect-pest attack that may reduce its final yield. The aim of this work was to evaluate the effect of artificial defoliation in different vegetative stages in the soybean crop. The experiment was implanted in the experimental area of the Instituto Federal Goiano Campus Morrinhos and conducted in a randomized block design, with eight treatments and four replications. The cultivar BRS Valiosa RR was submitted to the following treatments: T0: without defoliation; T1: removal of a leaflet by trefoil in V2 through V8; T2 removal of a leaflet by trefoil in V3 through V8; And so on until the last treatment T7: removal of a leaflet by trefoil in V8. The variables analyzed were: plant height, 1st pod insertion, chlorophyll index, number of branches, number of pods, number of grains per pod, weight of one thousand grains and final crop yield. Data were submitted to analysis of variance by the Scott-Knott test at $5 \%$ probability, using ASSISTAT software. It is concluded that continuous defoliation at a level of $33 \%$ in the initial stages of the crop reduces the size of the plant, the number of pods per plant and the final yield in the soybean crop.

Keywords: Glycine max; integrated pest management; productivity; reduction; trefoil.

\section{INTRODUÇÃO}

A cultura da soja (Glycine max (L.)
Merrill), apresenta grande importância
econômica para o mundo, sendo uma das
principais "commodities" produzidas no Brasil. A área cultivada com soja no Brasil na safra de 2015/2016 atingiu uma produção estimada de 100,9 milhões de toneladas, em 33,2 milhões de hectares, representando um acréscimo de $5 \%$ em relação à safra anterior de 2014/15, que alcançou 
produção de 96,1 milhões de toneladas, em 32,3 milhões de hectares. No estado de Goiás a área plantada foi de 3,2 milhões de hectares, alcançando produção de 8,5 milhões de toneladas e produtividade média de $2.649 \mathrm{~kg}$ por hectare (CONAB, 2016).

Suas grandes áreas de cultivo se devem ao relevante papel econômico que a cultura possui, apresentando alto potencial produtivo e valor nutritivo, além de ser matéria-prima indispensável para impulsionar diversos complexos agroindustriais (DALL'AGNOL, 2016).

A cultura da soja, durante todo o ciclo, está sujeita a diversos fatores, bióticos e abióticos, que podem comprometer seu processo fotossintético, desta forma, impedido que a planta expresse todo seu potencial. Para fatores bióticos, podemos destacar os insetos desfolhadores que promovem redução na área foliar da planta e, consequentemente, reduz sua taxa fotossintética (GALON et al., 2010).

Nos dias atuais, existem inúmeras estratégias de manejo para realizar o controle de insetos-pragas. Entre elas temos o manejo integrado de pragas (MIP) que consiste no conjunto de práticas racionais que visam minimizar impactos econômicos, sociais e ambientais, sugerindo um sistema de cultivo menos agressivo para a agricultura (GUEDES et al., 2006).

O MIP segue a premissa de que nem todo inseto é considerado praga, consequentemente, nem todo inseto precisa ser controlado. De acordo com Bueno et al. (2010), deve-se observar o nível da população infestante e se a cultura tolera a injúria sofrida sem reduzir sua produtividade.

A decisão de qual será o melhor momento para controlar insetos-praga na lavoura varia muito de cultura para cultura. O MIP determina que desfolhas de $30 \%$ no estádio vegetativo e $15 \%$ no reprodutivo não provocam redução na produtividade para a cultura da soja (EMBRAPA, 2013). Entretanto, os atuais níveis de ação recomendados para a cultura da soja são os mesmos estabelecidos na década de 70 , não levando em consideração o surgimento de novas cultivares no mercado, mais produtivas e com diferentes hábitos de crescimento. Portanto, o presente estudo objetivou analisar a influência de desfolhas na cultura da soja, cultivar BRS Valiosa $\mathrm{RR}$, em diferentes estádios vegetativos.

\section{MATERIAL E MÉTODOS}

O experimento foi realizado no município de Morrinhos-GO, a área experimental do Instituto Federal Goiano - Campus Morrinhos ( $1748^{\prime} 48,93^{\prime \prime}$ S; $49^{\circ} 12^{\prime} 6^{\prime \prime} \mathrm{W}$; $885 \mathrm{~m}$ de altitude), durante o ano agrícola 2015/2016 (dezembro a março). O clima da região é caracterizado como $A w$, segundo a classificação de Köppen-Geiger. A precipitação durante o período do experimento foi de aproximadamente $1000 \mathrm{~mm}$, temperatura máxima de $32{ }^{\circ} \mathrm{C}$ e mínima de $18{ }^{\circ} \mathrm{C}$. O solo é classificado como Latossolo Vermelho distrófico, de textura argilosa, sendo a topografia do terreno plana a levemente ondulada.

$O$ delineamento experimental foi o de blocos casualizados com oito tratamentos e quatro repetições, totalizando 32 parcelas experimentais. A parcela experimental foi constituída de cinco linhas de $5,0 \mathrm{~m}$ de comprimento, espaçadas 0,50 metros entrelinhas e 14 plantas por $\mathrm{m}$, densidade populacional de 280 mil plantas por hectare. Foram consideradas como área útil as três linhas centrais por um metro de comprimento, constituindo uma área de $1,5 \mathrm{~m}^{2}$. Os tratamentos estão apresentados na tabela 1. 
Tabela 1. Tratamentos, descrição e nível empregado de desfolha artificial em diferentes estádios vegetativos de plantas de Soja BRS Valiosa RR.

\begin{tabular}{ccc}
\hline Tratamento & Descrição & $\begin{array}{c}\text { Nível de } \\
\text { desfolha }\end{array}$ \\
\hline T0 & Remoção de todos folíolos centrais por trifólio em V2 até V8* & $0 \%$ \\
T1 & Remoção de todos folíolos centrais por trifólio em V3 até V8* & $33 \%$ \\
T2 & Remoção de todos folíolos centrais por trifólio em V4 até V8* & $33 \%$ \\
T3 & Remoção de todos folíolos centrais por trifólio em V5 até V8* & $33 \%$ \\
T4 & Remoção de todos folíolos centrais por trifólio em V6 até V8* & $33 \%$ \\
T5 & Remoção de todos folíolos centrais por trifólio em V7 até V8* & $33 \%$ \\
T6 & Remoção de todos folíolos centrais por trifólio em V8* & $33 \%$ \\
T7 & & $33 \%$ \\
\hline
\end{tabular}

*escala fenológica de Fehr e Caviness (1977).

A semeadura da soja BRS Valiosa RR, cultivar transgênica com tolerância ao herbicida glifosato, hábito de crescimento determinado, flor roxa, hilo preto, pertencente ao grupo de maturidade relativa 8.1., foi semeada de forma mecanizada no dia 10/12/2015. A adubação de semeadura consistiu na aplicação da dose de 428 $\mathrm{kg} \mathrm{ha}{ }^{-1}$ do fertilizante granulado 08-28-18. O manejo fitossanitário e de plantas daninhas foram realizados conforme recomendações técnicas para a cultura na região.

Os tratamentos foram feitos a partir do $16^{\circ}$ dia após a semeadura, quando mais de $50 \%$ das plantas já apresentavam o primeiro trifólio completamente expandido, definido como estádio V2 (FEHR; CAVINESS, 1997). A desfolha foi realizada por meio de corte com tesoura, eliminando sempre o folíolo central de cada trifólio, perfazendo o nível de $33,33 \%$ de dano foliar.

$O$ índice de clorofila foi determinado pelo equipamento Clorofilog SPAD-502 Plus, logo após a última desfolha em 10 plantas selecionadas ao acaso dentro da área útil da parcela. A altura de inserção da primeira vagem $(\mathrm{m})$ e a altura de planta $(\mathrm{m})$ foram determinadas em 10 plantas selecionadas ao acaso dentro da área útil, no momento da colheita aos 110 dias após a semeadura.

A colheita foi realizada manualmente e, durante a mesma, foram selecionadas 10 plantas da área útil para determinação dos componentes de rendimento da soja (número de ramos por planta, número de vagens por planta e número de grãos por vagem). Para determinação da produtividade $\left(\mathrm{kg} \mathrm{ha}^{-1}\right)$ e peso de 1.000 grãos $(\mathrm{g})$ todas as plantas da área útil foram trilhadas.

Os dados foram submetidos à análise de variância e as médias comparadas pelo teste de Scott-Knott a 5\% de probabilidade, por meio do software ASSISTAT 7.7 Beta (SILVA; AZEVEDO, 2009).

\section{RESULTADOS E DISCUSSÃO}

$\mathrm{Na}$ Tabela 2 estão apresentados os valores para cada tratamento das variáveis analisadas referentes à altura de plantas (AP), inserção de 10 vagem (IPV), índice de clorofila (IC), número de ramos (№ R), número de vagens (№ V), número de grãos por vagem (№ G/V), peso de mil grãos (PMG) e produtividade (P). 
Tabela 2. Alturas de plantas (AP), altura de inserção da 1a vagem (IPV), índice de clorofila (IC), número de ramos por planta (№R), número de vagens por planta (№V), número de grãos por vagem (№G/V), peso de 1000 grãos (PMG) e produtividade (P) da soja cv. BRS Valiosa RR sob desfolhas em Morrinhos-GO, 2016.

\begin{tabular}{ccccccccc}
\hline Desfolhas & AP & IPV & IC & No R & No V & No G/V & $\begin{array}{c}\text { PMG } \\
\text { (g) }\end{array}$ & (Kg) \\
\hline T0 - 0\% & (cm) & (cm) & $\left(\mathrm{mg} \mathrm{m}^{2}\right)$ & & & & & \\
T1 - 33\% V2 a V8 & $50,78 \mathrm{a}$ & 3,95 & 42,32 & 3,53 & $63,85 \mathrm{a}$ & 1,93 & 120,5 & $2.931,67 \mathrm{a}$ \\
T2 - 33\% V3 a V8 & $50,85 \mathrm{~b}$ & 4,48 & 42,02 & 3,10 & $48,38 \mathrm{~b}$ & 2,01 & 118,0 & $2.268,33 \mathrm{~b}$ \\
T3 - 33\% V4 a V8 & $51,68 \mathrm{~b}$ & 4,85 & 40,45 & 3,35 & $49,85 \mathrm{~b}$ & 2,01 & 120,0 & $2.760,00 \mathrm{a}$ \\
T4 - 33\% V5 a V8 & $49,80 \mathrm{~b}$ & 3,83 & 40,99 & 3,03 & $48,43 \mathrm{~b}$ & 1,96 & 117,0 & $2.771,67 \mathrm{a}$ \\
T5 - 33\% V6 a V8 & $52,40 \mathrm{~b}$ & 4,05 & 41,27 & 3,50 & $59,70 \mathrm{a}$ & 2,10 & 122,0 & $3.046,67 \mathrm{a}$ \\
T6 - 33\% V7 a V8 & $56,15 \mathrm{a}$ & 4,30 & 41,08 & 3,58 & $54,38 \mathrm{a}$ & 2,04 & 122,0 & $2.886,67 \mathrm{a}$ \\
T7 - 33\% em V8 & $58,18 \mathrm{a}$ & 4,75 & 40,43 & 3,08 & $50,95 \mathrm{a}$ & 1,93 & 129,0 & $3.050,00 \mathrm{a}$ \\
\hline
\end{tabular}

GL

Quadrado médio

\begin{tabular}{cccccccccc}
\hline Bloco & 3 & $5,93^{* *}$ & $8,74^{* *}$ & $0,99 \mathrm{~ns}$ & $4,35 *$ & $2,41 \mathrm{~ns}$ & $0,33 \mathrm{~ns}$ & $0,51 \mathrm{~ns}$ & $0,63 \mathrm{~ns}$ \\
Tratamento & 7 & $4,62 * *$ & $1,74 \mathrm{~ns}$ & $0,70 \mathrm{~ns}$ & $1,46 \mathrm{~ns}$ & $3,76 * *$ & $0,79 \mathrm{~ns}$ & $1,73 \mathrm{~ns}$ & $2,71 *$ \\
\hline C.V. \% & - & 6,92 & 14,06 & 4,01 & 13,84 & 12,41 & 6,45 & 5,12 & 13,85 \\
\hline
\end{tabular}

**: significativo ao nível de $1 \%$ de probabilidade; *: significativo ao nível de $5 \%$ de probabilidade; ns: não-significativo; C.V.: coeficiente de variação; GL: graus de liberdade.

A análise de variância apontou que a desfolha de $33 \%$ nos estádios iniciais, tem potencial para influenciar na altura final da planta. A maior redução na altura das plantas de soja foi observada quando as desfolhas iniciaram nos estádios de V2 a V6 (Tabela 2).

Bueno et al. (2010) em ensaio realizado no município de Morrinhos - GO utilizando cultivares de soja com ciclo determinado e indeterminado, visualizaram que quando a cultura da soja foi submetida à desfolha de $33 \%$ em todo seu estádio vegetativo, a altura final de planta foi reduzida em relação às plantas que não sofreram desfolha ou de menor intensidade.

Neumaier et al. (2000) e Peluzio et al. (2004) explicam que essa redução na altura da planta pode estar vinculada à dependência da planta na produção de fotoassimilados, que são produzidos pelas folhas completamente expandidas. Este argumento esclarece, parcialmente, porque a redução no porte das plantas ocorreu somente nos primeiros tratamentos. Pode ser devido às folhas fontes (mais velhas) já terem recebido a desfolha, e consequentemente, as mesmas não apresentarem a eficiência das plantas que ainda se encontravam ilesas.

Por outro lado, a redução na altura das plantas pode estar ligada somente ao momento em que foi realizada a desfolha, pois na fase de desenvolvimento tardio, V7, a planta já havia atingido sua altura máxima, e por isso a desfolha iniciando neste momento não foi prejudicial para a altura das plantas.

A altura de inserção da primeira vagem não sofreu alterações pelos tratamentos aplicados sobre as plantas. Esses resultados estão em conformidade com o obtido por Bahry et al. (2013), testando o desempenho da soja em função da desfolha em diferentes estádios vegetativos, verificaram que não houve diferença significativa entre os tratamentos para o parâmetro inserção de primeira vagem.

Bahry et al. (2013) esperavam que a altura de inserção da primeira vagem fosse superior na haste de plantas que sofressem desfolhas, em função do aborto natural desses, ou pela sua não formação, devido à falta de 
folhas no terço correspondente para produzir fotoassimilados, porém, tal situação não foi evidenciada.

Efeitos significativos não foram observados entre os tratamentos para índice de clorofila (Tabela 2). Souza et al. (2014), compararam o índice de clorofila dentro de cada estádio fenológico e visualizaram que, independente do nível e do estádio onde são feitas as desfolhas, nenhum dos tratamentos apresentou variação significativa quando comparado às testemunhas sem desfolhas, corroborando com o resultado encontrado no presente estudo.

Para número de ramos por planta não se constatou diferença significativa entre os tratamentos. Mauad et al. (2009) verificaram que plantas com folhagem mais adensada possuem menor quantidade de ramos produtivos do que plantas menos adensadas. Isso é devido a competição intra-específica das plantas pelos mesmos fatores do ambiente, sendo um dos principais a luz, ou seja, quanto maior for o adensamento, menor será a disponibilidade de fotossimilados, e consequentemente afetara a interceptação da planta.

Esperava-se que as desfolhas pudessem maior aeração na folhagem da planta, e como consequência haveria maior número de ramificações. Entretanto não foi observado tal evento no nível de desfolha utilizado (Tabela 2).

Com relação ao número de vagens por planta, foi possível observar diferença significativa nos tratamentos com desfolha, especificamente nos tratamentos de T1, T2, T3 e $\mathrm{T} 4$, onde os mesmos apresentaram redução média de $25 \%$ no número de vagens quando comparados com a testemunha (Tabela 2). Tal resultado não condiz com o observado por Bahry et al. (2013) e Souza et al. (2014), que não observaram alteração no número de vagens por planta devido a desfolha.

Diogo et al. (1997), avaliando a influência da remoção de folhas em vários estádios de desenvolvimento da soja, observaram que desfolhas mais drásticas nos estádios reprodutivos, podem ocasionar maior redução no número de vagens. Mas quando desfolhas realizadas nos níveis de $66 \%$, a partir de V3, apresentaram acentuada redução no número de vagens em relação à testemunha sem desfolha. Já para Parcianello et al. (2004), o número de vagens foi reduzido somente quando as desfolhas foram realizadas nos estádios reprodutivos.
Mesmo que em alguns trabalhos não apontaram variação na quantidade de vagens formadas pelas plantas, quando as mesmas são submetidas a desfolhas dentro do nível de controle estabelecido pelo MIP, no presente estudo a desfolha causou redução na produção de vagens pela planta de soja. Sediyama et al. (1985) e Pratissoli et al. (2012), esclarecem que em razão do aumento do tamanho dos drenos nas épocas de florescimento e durante o enchimento das vagens, ocorrem picos de atividade fotossintética indicando maior necessidade de produtos fotossintéticos para a planta realizar sua função de produzir e encher vagens. Assim, desfolhas tem o potencial para ocasionar perdas no número de vagens por planta, porque não ocorre fotossíntese suficiente para a planta realizar esta função.

Em nenhum dos tratamentos foi observada diferença para o parâmetro número de grãos por vagem, proporcionando média de dois grãos por vagem. Estes resultados estão de acordo com os obtidos por Diogo et al. (1997), Peluzio et al. (2004) e Bahry et al. (2013), que não encontraram diferença significativa mesmo trabalhando em níveis mais elevados de desfolha das plantas de soja (33\% e 66\%). Mundstock e Thomas (2005), explicam que o número de grãos por vagem é um dos componentes que apresentam menor variação independente da situação de cultivo. Justificando que esse fator é muitas vezes uma característica específica de cultivar para cultivar.

$O$ peso de mil grãos (PMG) não diferiu entre os diferentes tratamentos (120 g) (Tabela 2). Peluzio et al. (2004), também não encontraram alteração no PMG quando a soja foi submetida à desfolha de $33 \%$ no estádio vegetativo em relação à testemunha, mas quando esse mesmo nível ocorreu no estádio reprodutivo reduziu parcialmente o peso de mil grãos. Tal redução pode estar vinculada ao decréscimo na disponibilidade de fotossimilados para o enchimento de grãos (PELUZIO et al., 2002). Isso mostra que a variável, peso de mil grãos, não sofre alteração quando o MIP é respeitado. Sendo assim, possibilita ao agricultor ter um período para tomada de decisão na forma de controle que será utilizada na área, e em alguns casos, até reduzindo o número de aplicações para controle de insetos desfolhadores.

A produtividade da soja foi reduzida pela desfolha nos estádios iniciais (V2 e V3), chegando 
a decréscimos de $20 \%$ (Tabela 2). Resultado este que não se assemelha ao encontrado por Bahry et al. (2013), que trabalharam com uma única desfolha da planta de soja na fase vegetativa em índices superiores, sem promover redução da produtividade. Uma justificativa que pode ter influenciado para esta diferença nos resultados é que cada experimento foi conduzido com cultivares e ambientes diferentes, além da forma como a desfolha foi aplicada a planta de soja.

Em estudo realizado por Fipke et al. (2013), onde aplicaram desfolhas em duas cultivares de hábitos de crescimento determinado e indeterminado, observaram que na cultivar com hábito de crescimento determinado ocorreu redução na produtividade quando desfolhas em nível de $33 \%$ foram feitas durante todo o ciclo vegetativo, corroborando com o resultado exposto no presente trabalho.

Podemos observar que a redução na produtividade da soja devido a desfolha é mais expressiva quando a mesma é realizada de forma continua e a cultivar possui hábito de crescimento determinado.

\section{CONCLUSÃO}

Nas condições do presente estudo, a soja cV. BRS Valiosa RR sofreu influência negativa da desfolha ocorrida na fase vegetativa, com redução da altura de planta, no número de vagens por planta e na produtividade.

\section{REFERÊNCIAS}

BAHRY, C. A.; VENSKE, E.; NARDINO, M.; ZIMMER, P. D.; SOUZA, V. Q.; CARON, B. O. Desempenho agronômico da soja em função da desfolha em diferentes estádios vegetativos. Revista Tecnologia e Ciência Agropecuária, v.7, n. 4, p. 19-24, 2013.

BUENO, A. F.; BATISTELA, M. J.; MOSCARDI, F. Níveis de desfolha tolerados na cultura da soja sem a ocorrência de prejuízos à produtividade. Londrina: Embrapa Soja, 2010. (Circular técnica 79).

CONAB - Companhia Nacional de Abastecimento. Acompanhamento da safra brasileira de grãos 2015/2016 - Quarto levantamento Janeiro/2016. Disponível em: swww.conab.gov.br>. Acesso em: 17 jun. 2016.
DALL'AGNOL, A. A Embrapa Soja no contexto do desenvolvimento da soja no Brasil. Brasília: Embrapa, 2016.

DIOGO, A. M.; SEDIYAMA, T.; ROCHA, V. S.; SEDIYAMA, C. S. Influência da remoção de folhas, em vários estádios de desenvolvimento, na produção de grãos e em outras características agronômicas da soja (Glycine max (L.) Merrill)'. Revista Ceres, v. 44, n. 253, p. 272-285, 1997.

\section{EMBRAPA. Tecnologias de produção de soja região central do Brasil, 2014. Londrina: Embrapa} Soja, 2013.

FEHR, W. R.; CAVINESS, C. E. Stages of soybean development. lowa: Editora lowa State University of Science and Technology, 1977.

FIPKE, M. V.; HELLWING, L.; TRECHA, C. O.; MEDINA, L. B.; OLIVEIRA, A. C. B.; AFONSO-ROSA, A. P. S. Efeito de diferentes intensidades de desfolha na produtividade de cultivares de soja de hábito determinado e indeterminado. CONGRESSO DE INIVIAÇÃO CIENTÍFICA DA UFP, 23, Pelotas, 2013. Anais... Pelotas: Universidade Federal de Pelotas, 2013.

GALON, L.; TIRONE, S. P.; ROCHA, A. A.; SOARES, E. R.; CONCENÇO, G.; ALBERTO, C. M. Influência dos fatores abióticos na produtividade da cultura do milho. Revista Trópica: Ciências Agrárias e Biológicas, v. 4, n. 3, p.32, 2010.

GUEDES, J. V. C.; FARIAS, J. R.; GUARESCHI, A., ROGGIA, S.; LORENTZ, L. H. Capacidade de coleta de dois métodos de amostragem de insetospragas da soja em diferentes espaçamentos entre linhas. Revista Ciência Rural, v. 36, n. 4, p.12991302, 2006.

MAUAD, M.; SILVA, T. L. B.; ALMEIDA, A. I. N.; ABREU, V. G. Influência da densidade de semeadura sobre características agronômicas na cultura da soja. Revista Agrarian, v.3, n. 9, p. 175181, 2010.

MUNDSTOCK, C. M.; THOMAS, A. L. Soja: fatores que afetam o crescimento e o rendimento de grãos. Porto Alegre: Editora Evangraf, 2005.

NEUMAIER, N.; NEPOMUCENO, A. L.; FARIAS, J. R. B.; OYA, T. Estresses de ordem ecofisiológica. Passo Fundo: Embrapa Trigo, p. 45-65, 2000. 
PARCIANELLO, G.; COSTA, J. A.; PIRES, J. L. F.; RAMBO, L.; SAGGIN, K. Tolerância da soja ao desfolhamento afetada pela redução do espaçamento entre fileiras. Revista Ciência Rural, v. 34, n. 2, p. 357-364, 2004. $<$ http://dx.doi.org/10.1590/S010384782004000200004>.

PELUZIO, J. M.; BARROS, H. B.; ROCHA, R. N. C.; SILVA, R. R.; NASCIMENTO, I. R. Influência do desfolhamento artificial no rendimento de grãos e componentes de produção da soja (Glycine max (I.) Merril). Revista Ciência e Agrotecnologia, v. 26, n. 6, p. 1197-1203, 2002.

PELUZIO, J. M.; BARROS, H. B.; BRITO, E. L.; SANTOS, M. M.; SILVA, R. R. Efeitos sobre a soja do desfolhamento em diferentes estádios fenológicos. Revista Ceres, v. 51, n. 297, p. 575585, 2004.

PRATISSOLI, D.; SCHMILDT, E. R.; AMARAL, J. A. T.; SCHMILDT, O. Níveis de desfolha artificial para simular perdas na produtividade do feijoeiro comum. Revista Scientia Agraria Paranaensis, v. 11, n. 3, p. 68-76, 2012.

SEDIYAMA, T.; PEREIRA, M. G.; SEDIYAMA, C.S.; GOMES, J. L. L. Cultura da soja: 1ạ parte. Viçosa: UFV, 1985. p. 96.

SILVA, F. A. S.; AZEVEDO, C. A. V. Assistência Estatística - Assistat versão 7.7 beta. Departamento de Engenharia Agrícola do CTRN, Universidade Federal de Campina Grande Campus de Campina Grande - PB. 2009. Disponível em: <http://www.assistat.com/indexp.html>. Acesso em: 02 julho 2018.

SOUZA, V. Q.; NARDINO, M.; FOLLMANN, D. N.; BAHRY, C. A.; CARON, B. O.; ZIMMER, P. D.

Caracteres morfofisiológicos e produtividade da soja em razão da desfolha no estádio vegetativo. Revista Jaboticabal, v. 42, n. 3, p. 216-223, 2014.

Recebido para publicação em 02/02/2018

Revisado em 29/06/2018

Aceito em 06/07/2018 